Philosophical Issues, 15, Normativity, 2005

\title{
MORAL PHENOMENOLOGY AND MORAL THEORY
}

\author{
Terry Horgan and Mark Timmons \\ University of Arizona
}

Appeals to moral phenomenology - the phenomenology of moral experience - are common in moral philosophy, particularly in metaethical inquiry. But as far as we can tell, the topic of moral phenomenology has not typically been center stage - a focus of inquiry in ethics. And so, going back at least to the writings of G. E. Moore (and with some notable exceptionssee below), very little has been written about the nature and significance of moral phenomenology. This is not only the case in connection with metaethical inquiry; the same lack of inquiry is to be found among those whose main interests in ethics are in normative moral theory.

As we just mentioned, there are some exceptions - and the exceptions will help us zero in on our target in what we say below. So let us mention two thinkers whose works we will use as a starting point for thinking about moral phenomenology. First, in 1938, philosopher and gestalt psychologist Wolfgang Köhler published The Place of Value in a World of Facts, whose aim was to make sense of the ubiquitous notion of 'requiredness' that is common to logic, scientific inquiry, and what we may just call 'practical inquiry'. All of these fields involve requiredness or what we now call normativity, and Köhler thought that the evolving naturalistic picture of the world that is presented to us by science does not clearly leave a place for normativity. His task was to find a place for it. And his method for doing so was to focus first on providing a phenomenological description of experiences of requiredness. Maurice Mandelbaum's 1955 book, The Phenomenology of Moral Experience, is less grand in scope than is Köhler's - as his title indicates, Mandelbaum is concerned with our moral experiences. But the specific focus of his book is on the phenomenology of moral requiredness and, like Köhler, he makes a case for the methodological priority of phenomenological description in carrying out a certain philosophical project in ethics. While Köhler is concerned with the 
metaphysical task of finding a place for value in a world of fact, Mandelbaum is primarily concerned to make progress in the search for an adequate normative moral theory. Both thinkers held that phenomenological description is the basis for accomplishing these tasks.

The contrast in focus and method of these two books with what has gone on in analytic moral philosophy from the early twentieth century until the present day is striking. And no doubt there are various philosophical (and perhaps sociological) trends that would explain this. However, we won't be engaged in such speculation here. Rather, our main purposes in this paper are (1) to bring into focus issues about moral phenomenology, in an effort to get clear about what 'phenomena' philosophers are (or should be) referring to when they appeal to alleged facts of moral phenomenology, and then (2) to raise and briefly explore a number of questions about moral phenomenology with an eye toward potential philosophical payoff for moral theory that phenomemological description of moral experience may yield. Some of the questions we have in mind are about the scope, unity, and distinctiveness of moral phenomenology, and others are about the philosophical motivation for, and potential payoff from, engaging in a phenomenological approach to morals. Here, then, are the questions:

- Which phenomena does moral phenomenology purport to describe? (scope)

- How much unity is there among the various sorts of experiences characteristic of moral experience? (unity)

- What (if anything) is distinctive of moral experiences? (distinctiveness)

- Are there any reasons to believe that a phenomenological approach to philosophical questions in moral theory is superior to, or at any rate usefully supplemental to, other approaches? (motivation)

- What results might one reach about philosophical issues in moral theory (including both normative moral theory and metaethics) on the basis of a phenomenological description of moral experience? (potential payoff)

In the first three sections, we will spend time discussing the alleged subject matter and methodology of phenomenological investigation, using Mandelbaum as our primary resource. Then in the following sections (IVVIII), we will proceed to consider the five questions just mentioned. This paper is necessarily programmatic; we cannot possibly develop in a single paper a phenomenology of moral experience - which would be required for providing complete and compelling answers to our questions. But if we are right about the philosophical significance of moral phenomenology, we will have accomplished what we have set out to do. Perhaps a more fitting title for our paper would be: 'Prolegomea to any Future Phenomenology of Morals'. 


\section{Moral Phenomenology—narrowing in on what it is about}

In metaethical inquiry, talk of 'moral phenomenology' is used very broadly to include such deeply embedded phenomena as: (1) the grammar and logic of moral thought and discourse; (2) people's 'critical practices' regarding moral thought and discourse (e.g., the assumption that genuine moral disagreements are possible), and (3) the what-it-is-like features of concrete moral experiences. Henceforth, we will concentrate on the third, what-it-is-like features of concrete moral experiences. In so doing, we do not deny that there is or can be a phenomenology associated with the items mentioned in the first two categories. For example, if there is a what-it-is-likeness to inferring generally, then there will be a what-it-is-likeness to drawing moral inferences and engaging in moral reasoning generally. However, whatever phenomenology is characteristic of moral inference, we will take it to be of secondary importance and we will further suppose that it is experiences with logically non-complex moral content that are phenomenologically primary.

\section{Mandelbaum's moral phenomenology: its aims, subject matter, and method}

In this section and the next, we will follow the lead of Mandelbaum, whose account of moral phenomenology we think is a suitable starting point for an inquiry into this topic, beginning in this section with an exposition of his views on the (1) aims, (2) subject matter, and (3) method of moral phenomenology. In the next section, we will consider his account of the phenomenology of one type of moral judgment that seems most central to his overall view.

1. Aims. Mandelbaum's phenomenological method involves both philosophical and practical aims. The primary philosophical aim is to make progress in moral theory for the further practical purpose of having a basis for dealing with moral conflict. The chief philosophical task Mandelbaum sets for himself is to determine whether what people call 'moral' judgments form a single genus (in virtue of sharing some feature(s) in common) and also to determine what sorts them into distinct species (37-8). ${ }^{1}$ The relation between this enterprise and the practical concern with resolving moral conflict is (according to Mandelbaum) that only by undertaking this sort of phenomenological approach to investigating the sorts of similarities and differences there may be in moral judgments can one approach the question of whether there may be some valid moral norms to which we might appeal to adjudicate moral conflict. (We return to questions of rationale below in section VII.)

2. Subject matter. For Mandelbaum, "the phenomenological approach to ethics starts from a point which all paths [approaches to ethics] must eventually cross: a direct examination of the data of men's moral consciousness" (30). And he takes this kind of direct examination to be a matter of examining moral judgments. 
Mandelbaum recognizes the common distinction between judgments of moral obligation and judgments of value (moral worth) - though for him the most phenomenologically significant distinction among types of moral judgment is between direct and removed judgments. Judgments of the former sort are about rightness or wrongness rather than value, and furthermore are "made by an agent who is directly confronted by a situation which he believes involves a moral choice on his part" (45). Removed moral judgments are socalled because they are made from a spectator's point of view. Removed deontic judgments have as their focus the actions of another or one's own past self; removed judgments of value are either about specific character traits (the virtues and vices) or about the overall character of some individual.

3. Method. Mandelbaum distinguishes two species of what he calls the 'phenomenological approach' to ethics. The first type, which he labels as 'contentual', is the familiar method of reflective equilibrium in which one seeks to uncover general principles that 'cohere' (in their contents) with more particular moral judgments. By contrast, there is the 'generic' approach which abstracts from the content of moral judgments and attempts to "uncover that which - whatever they assert - all have in common" (36). Matters relating to the attitudes of a person making a moral judgment might seem to be what remains if we abstract from matters of content. But, according to Mandelbaum, any 'purely attitudinal' approach (in effect, the sort of method championed by metaethical non-cognitivists) is too myopic for a proper generic understanding of moral judgment. Rather, he advocates a 'structural' approach:

What characterizes this approach is the fact that it treats moral experience as a complete judgmental act. Not only are the attitudes which are present and the content which is affirmed to be considered, but it is crucial for such an approach to examine each of these in relation to the situation in which the judgment is made. Therefore, instead of abstracting either content or attitude from the total situation, we shall first inquire into the manner in which a situation appears to one who makes a moral judgment; we shall then attempt to interpret the other two elements in terms of their relationship to this situation. (40).

It is rather hard to tell from this abstract description how the 'structural' approach is supposed to proceed. So let us consider the basic elements of Mandelbaum's structural method, as applied to direct moral judgments.

\section{Mandelbaum's phenomenology of direct moral judgments}

Direct moral judgments, as earlier noted, are made by an agent in the context of being in a situation in which she takes herself to confront a moral choice. Mandelbaum's phenomenological description of the experience in which this kind of judgment is made involves, as it were, two layers. First, he describes 
the experience of feeling obligated to perform or refrain from performing some envisioned action and, second, he describes what he takes to be the phenomenological basis of the feeling in question. Let us take these up in order.

According to Mandelbaum, the experience of moral obligation involves a felt demand which is experienced as a force which, he claims, like all forces can only be described by referring to its experienced origin and direction:

It is my contention that the demands which we experience when we make a direct moral judgment are always experienced as emanating from "outside" us, and as being directed against us. They are demands which seem to be independent of us and to which we feel that we ought to respond (54).

So, for Mandelbaum, the demand characteristic of direct moral judgments is 'reflexive' - it is directed against the agent making the judgment - and its origin is experienced as independent of the agent. As he goes on to explain, this sense of 'independence' is what gives direct moral experiences their 'objective' flavor in that the demand appears to come from features of the situation that one confronts and that are themselves independent of one's desires, preferences, and aversions.

So the first layer of phenomenal description of direct moral judgments is that they are experienced as objectively grounded reflexive demands. The second layer concerns what one's experiences reveal (within their phenomenology) about the basis of the felt demand which Mandelbaum identifies as the experientially-presented relational characteristic of fittingness (and its counterpart, unfittingness). The idea is that in direct moral judgment one experiences a demand on oneself that one perform (or refrain from performing) some particular action (on some occasion), and one experiences this demand as itself based on an experience of objective fittingness or unfittingingness between such an action and the features of the situation. In such situations, one experiences certain features of the environment or situation confronting one as 'calling forth' some action on one's part. Here is one example. I arrive at my office on the last day of regular classes for the semester, check my calendar, and note that I have an appointment scheduled for 9:30 that morning with a student. I now recall having made this appointment and realize that, because it is the end of the semester, it is quite important for the student that I keep it. I had hoped to answer a backlog of email during the morning hours on this day, but given the circumstances (which include my awareness of having made the appointment, my awareness of the significance of the appointment to the student, particularly as it may affect her grade in my class, and my awareness of many other features that I take to be relevant to what choices I make this morning) I experience a felt demand upon me to keep the appointment by now engaging in various preparations (re-reading the draft of her paper, opening my office door as 9:30 approaches, taking the stack of books off the chair used by visitors to 
my office, and so on). The various activities just mentioned strike me as contemplated actions of mine that are called for by the present complex of circumstances. There are many incompatible activities that I might engage in rather than the ones just mentioned, but my experience here is that the appointment-related activities are (compared to my other options) most fittingly related to the 'outside' circumstances at least as I take them to be. The experience of some range of activities being most fitting to one's current circumstances - the apprehension of this sort of fittingness - is, for Mandelbaum, the basis of the felt demand that is characteristic of the phenomenology of first person, direct moral obligation.

The phenomenological connection between the sort of reflexive demand experienced in direct moral judgments on one hand, and the apprehension of the fittingness or unfittingness of actions on the other, is this: the agent experiences the felt demand as resting upon, or evoked by, the apprehension of fittingness - rather than the other way around. This element of moral experience is part of one's sense of the objectivity of moral obligations. So, for instance, when I experience the demand to meet with my student for our appointment, the basis of this feeling is my apprehension of the relational fact that so acting is more fittingly related to what I take to be my current situation than any other alternative action (or series of actions) I might undertake instead. My apprehension of this sort of relational fact is what evokes the reflexive demand that is characteristic of direct moral judgments.

We hope that this short exegetic treatment of Mandelbaum's phenomenological description of but one type of moral judgment is sufficient to both acquaint the reader (if need be) with one aspect of Mandelbaum's nuanced moral phenomenology, and to illustrate the sort of project we have in mind with regard to talk of moral phenomenology. We now proceed to consider in order the five questions about moral phenomenology and moral theory that we announced earlier, devoting a section to each of them. What we have to say in response to these questions is necessarily tentative, given the size of the questions and the space of a single article. We offer our responses as first steps that are part of a larger project upon which we are embarking. ${ }^{2}$

\section{Scope}

Earlier, in section I, we explained that we mean to use the phrase 'moral phenomenology' in what we take to be its proper use to refer to the what-itis-likeness of concrete moral experiences. With some aspects of Mandelbaum's view on the table, we now want to say more about the scope of moral phenomenology. We intend our usage of 'moral phenomenology' to allow for the full range of moral experiences-experiences that need not involve just moral judgments narrowly construed (e.g., as occurrent beliefs that have arisen as a result of an occurrent judging process). 
Construed narrowly, a moral judgment is an occurrent moral belief, arrived at through a process of deliberative thinking; henceforth we will use the phrase 'deliberative moral judgment' for such a belief. ${ }^{3}$ For reasons we are about to explain, one needs to broaden the scope of moral experiences that are candidates for phenomenological investigation; the scope should include more than deliberative moral judgments. More precisely, we wish to call attention to the phenomenological aspects of: (1) moral judgments understood more broadly, viz., as occurrent beliefs that have moral content but that need not necessarily be preceded by deliberation or reflection; (2) moral comportment that arguably does not involve moral judgment as an aspect of the experience; (3) the psychological attitudes of believing in general and moral believing in particular; and (4) the psychological attitude of entertaining (without necessarily believing) claims with moral content. These, we will maintain, are four important possible foci of phenomenological investigation that should be recognized. Let us take them up in order.

1. Moral judgments. The main point we wish to stress here about the phenomenological investigation of moral judgments is that they should not be narrowly conceived. As we are using the term 'judgment', a moral judgment is an occurrent belief with moral content; but one should distinguish (along a continuum) cases ranging from moral beliefs formed in light of conscious deliberation to spontaneous moral beliefs not preceded by any conscious deliberation. Michael may stop and 'think through' the details of some situation calling for a moral response, and on that basis form the belief that he ought to forego a Sunday afternoon of watching basketball on television and finish the project he promised to have finished for Monday. The process of considering his options - thinking about how much he would enjoy the game, but also thinking about how it would interfere with his work, would break the promise, might jeopardize his job, and so forthleads him to judge that he morally ought, all things considered, to skip watching the game and bear down on the project. Contrast moral judgment which arises within a context of conscious deliberation with spontaneously judging (in the case made famous by Harman 1977: 4-5) that what the hoodlums are doing (in pouring gasoline on a helpless animal - a puppy, for example - and setting it on fire) is morally outrageous. One doesn't need to deliberate in this latter case; one has an immediate gut reaction that (suppose) is immediately expressed in thought by the sentence: 'That's outrageous!' And, of course, in between the two cases just described there is a range of cases involving more or less deliberation and thus more or less spontaneity in coming to have an occurrent belief with moral content. Certainly, then, moral phenomenology needn't be restricted to such deliberative moral judgment.

2. Ethical comportment. But perhaps one should allow (in addition to conscious moral beliefs, both deliberative and spontaneous) cases in which one responds in a morally appropriate way without consciously forming a 
moral belief at all — call this kind of experience, 'ethical comportment' . The idea is that in persons having a high degree of moral expertise, the phenomenology of their habitual responses to morally significant situations may not include making (or coming to have) a moral judgment as part of their experience. This strikes us as an important possibility that deserves further phenomenological investigation but will have to wait for another occasion.

The upshot of this discussion is that one should not assume that the proper subject matter under consideration is restricted to the phenomenology of deliberative moral judging-or even that it is restricted to the phenomenology of occurent moral belief (whether deliberative or spontaneous). ${ }^{5}$ Certainly, phenomenological description generally need not take occurrent beliefs as its exclusive focus. So, as a methodological starting point, phenomenological description of moral experience should not be thought of as concerned exclusively with what Mandelbaum attempts to describe in his book, even if one allows that his focus included conscious moral judgments broadly understood.

3. Moral judging. Even when one does focus specifically on moral judgment, there is some sorting out to do. In light of recent work by philosophers of mind on the alleged phenomenology of mental intentionality, one needs to notice that talk of the phenomenology of moral judgment covers two distinguishable factors. First, there is the phenomenology of moral judging - in which one 'comes down' on some moral issue-where the focus is on the distinctive phenomenology of forming and/or occurrently undergoing belief - as opposed to the phenomenology of forming and/or occurrently undergoing some other type of psychological attitude such as desiring, intending, hoping, suspecting, or whatever. Second, there is the phenomenology of moral entertaining - in which one holds before one's mind a specific moral claim or proposition. ${ }^{6}$

Concerning the phenomenology of judging, one important question concerns how properly to understand which sort of psychological state(s) one is in when one comes down on some moral issue-whether such states are simply beliefs, or are some other non-belief state (one that shares with belief the phenomenal characteristic of being a state in which the agent 'comes down' on the issue under consideration), or are a complex combination of belief and non-belief states. However the relevant psychological attitude-type is to be best understood, it should be kept in mind that there is a phenomenology of being in a state of this - a 'morally coming down upon' type.

4. Entertaining. The phenomenology of entertaining a moral content (thought) is distinctive of occurrently grasping or understanding the specific content in question and actively contemplating this content. It is distinct from the what-it-is-likeness of coming down one way or the other vis-à-vis a moral content. ${ }^{7}$ 
Among the issues worth investigating is the question of how the judging aspect and the entertaining aspect interact with one another phenomenologically, in moral experience. As a way into this issue, consider the logical structure of statements ascribing deontic judgments, a structure evidently revealed most explicitly via sentences containing an inner, descriptive, 'that'-clause embedded within an outer 'that'-clause with moral content - e.g., 'Jones believes that it ought to be that he apologizes to Smith'. Perhaps the distinctively 'ought-ish' phenomenal character of such a judgment involves not the experience of coming down in a 'how-things-are' manner with respect to a content expressible as 'that it ought to be that I apologize to Smith', but rather the experience of coming down in a 'how-things-ought-to-be' manner with respect to the non-normative content expressible as 'that I apologize to Smith'. I.e., perhaps 'ought' is phenomenologically bound up with the pertinent mode of believing - a 'believesought' way of believing, directed toward an 'inner' non-normative contentrather than being phenomenologically bound up with an 'outer' normative content which itself is the propositional object of a generic, how-it-is, mode of believing. Likewise, perhaps the phenomenology of entertaining an ought-claim is best characterized as something like hypothetically trying on, in thought, such an ought-belief with respect to a non-normative content. ${ }^{8}$

In sum, in order to take account of the entire range of moral experience, one should recognize at least four potential foci of phenomenological investigation in ethics: (1) experiences involving both deliberative and spontaneous moral judgments - call them judgmental moral experiences, (2) moral experiences that do not involve conscious moral judgment (cases of ethical comportment), (3) experiences constitutive of the psychological attitude of 'coming down' on some moral issue, and (4) experiences associated with grasping or understanding moral claims.

Here, then, are some questions about the scope of moral phenomenology that are more specific than the one with which we began:

- How is the phenomenology of ethical comportment to be understood?

- Does it differ from the phenomenology of judgmental moral experience?

- How does the phenomenology that is distinctive of understanding a claim with moral content differ from the phenomenology of accepting or rejecting such a claim?

- Does moral belief involve a phenomenologically distinctive type of believing (e.g., ought-believing) that is directed toward a non-normative content?

\section{Unity}

In order to tackle the question of what unity there might be across moral experiences, the following three interrelated questions should be addressed. (1) What is the scope of moral experience under consideration? 
(2) What are the experiential elements of moral experiences and how are they related? (3) How is the pertinent notion of unity to be understood? For reasons of space, in what follows we will continue to focus on what we have been calling judgmental moral phenomenology, and we will focus in particular on the sorts of psychological elements in judgmental moral experience that Mandelbaum considers. But we need to say a bit more about the issue of unity.

Assuming that there are distinct types of moral experience, there is the question of unity within some particular type, and there is also the question of unity across more than one type (possibly all). Call this the 'local/global' issue about unity. Strategically, one seeks out local unity within types of moral experience and, if one finds it, one compares the types. Now presumably, in examining whatever unity there might be in moral experience, one is looking for some common elements that are constitutive of those experiences. This leads directly to the second above-mentioned question. But one wants more than any old constitutive common elements. After all, it is easy to find some scheme for classifying such experiences that unifies them. One could, as many have, simply use broad categories of psychological state - say pro and con psychological attitudes (including beliefs) - to distinguish two main types of moral experience; automatically, one has unity within a type. This isn't very interesting. What is wanted is some interesting kind of unity, if it exists.

To focus thinking, let us consider the kind of unity that is often sought in standard normative moral theory-unity at the level of those nonnormative, underlying, 'natural' features possessed by items of moral evaluation (and the circumstances in which they are present). ${ }^{9}$ Let us also consider the bearing of moral phenomenology on the question of the extent to which types of judgmental moral experience are unified at the level of underlying features of circumstances that evoke moral judgments. And let us further distinguish two possible foci of judgmental moral experience that may have implications for questions of unity. First, one may look to the content of moral judgments for some sort of interesting unity, or second, one may look to psychological aspects other than content to find some interesting unity. And, of course, one may look to both. Again, space won't allow a full treatment of this issue. Nevertheless, in what follows, we wish to make a tentative case for two claims: (1) At one level of phenomenological description, some form of pluralism is most consistent with moral phenomenology; (2) however, at another level of description, there is unity across standardly recognized types of moral judgment.

We begin with the question of unity with regard to the contents of moral judgments. At the level of vocabulary together with straightforward connections of synonymy, a distinction can be made between deontic moral judgments on one hand (employing terms like 'right', 'wrong', 'ought' and their synonyms) and value judgments on the other (employing terms like 
'good', 'bad', 'virtuous', 'vicious' and their synonyms). This much does not take one very far. However, bearing in mind Mandelbaum's view that with direct moral judgments, at least, one experiences a felt demand (whose source is a set of facts that are partly constitutive of the concrete circumstance confronted on some occasion), one is naturally led to focus on those aspects of the circumstances that just judgments are somehow about. So, in considering the elements of concrete moral experiences that prompt or evoke moral judgments, one might proceed as follows. Start, say, with deontic judgments and ask whether concrete moral experiences involving such experiences reveal some common element or set of elements that would, in some interesting sense, unify those experiences. Here it is important to distinguish 'levels' at which one might hope to discover some unity that is manifest in the phenomenology. As we mentioned earlier, one traditional task of normative moral theory has been to investigate the 'underlying' natural features of actions (and the circumstances in which they are performed) to determine whether there are any property types (at the level of natural description) in virtue of which actions are (or are said to be) right or wrong. Monist theories propose that there is some single underlying feature; pluralist theories propose a small set of such underlying features. And while particularist theories agree with pluralists that there are a variety of underlying features, they deny the common pluralist idea that there is some fixed set of underlying features that are always morally relevant (when instantiated) and also have the same normative valence.

It would seem that when it comes to the mere phenomenology of moral experience in concrete cases (involving deontic judgments), such experiences do not comport with monism - rather, moral experiences of being obligated, for instance, seem to be evoked by a variety of factors that vary from one circumstance to another. The factors involved in feeling an obligation of gratitude, for example, differ from the factors involved in coming upon someone who is in need of help. Indeed, a virtue of versions of ethical pluralism (featuring a plurality of prima facie duties which collectively attempt to specify a small set of underlying features in virtue of which actions have the deontic status they do have) is that they are faithful to much concrete moral experience. ${ }^{10}$ Nevertheless, one might ask whether at some level more unity can be found than a Rossian view delivers.

As we have already indicated, Mandelbaum thought so. Recall that he worked with the distinction in moral judgment between deontic and value judgments, but he distinguished also between direct and removed judgmentson the basis of certain elements of phenomenology other than content. But, as we also indicated, he thought that direct moral judgments (deontic judgments made by agents who confront concrete situations calling upon them for a moral response) are unified by being apparent apprehensions of the relation of fit or unfit between some contemplated course of action and the morally relevant aspects of the situation. As we understand these 
notions, they are normative - an action is fitting to a situation when aspects of that situation provide reasons that make the action appropriate, and it is most fitting when the combination of reasons there are uniquely favor the action in question. Mandelbaum (71) claimed that this relation was as he put it, "naturalistic" - quotes included - though about the only explanation he offers for this remark is that this kind of relation is also found in other sorts of non-moral experience.

But Mandelbaum went further: he claimed that this element of perceived fit or unfit was at the bottom of experiences having to do with removed moral judgments. Without getting into the details, the basic idea is this. Removed judgments of obligation involve an apparent apprehension of a relation of fit or unfit between the contemplated action or omission of some agent (either someone else or one's past self) in a situation that he or she confronts (or did, or might have) and in which the action is (or was, or might be) performed. A similar apparent apprehension is involved in judgments of value - judgments that are made from a spectator's viewpoint (and thus are removed) and which have to do with some character trait or a person's overall character. According to Mandelbaum, "The traditionally recognized virtues are... precisely those traits of character which provide fitting answers to the ever-recurring demands which all men face" (150).

The obvious question to raise in connection with Mandelbaum's account of the unity of judgmental moral experience is this: How interesting is this sort of unity? After all, in order for the appeal to fittingness and unfittingness to be an interesting sort of unity, it must be distinct enough from one's sense of the rightness of an action or the goodness of a character trait that its presence in moral experiences helps illuminate their connectedness in a way in which merely appealing to rightness and goodness per se does not. Here, in effect, one is considering whether what one takes to be a pair of normative notions (fittingness and unfittingness) pick out features that are part of common moral experiences (involving judgments of right and good) and which underlie moral judgments. And it is worth noting that, on Mandelbaum's view about unity, judgmental moral experiences do involve the experience of something essentially relational having a certain identifiable structure. In particular, the experienced relation of fittingness involves an essential 'internal connection' between an action and circumstance; this experienced structural link, we think, may well have implications for issues in moral theory. Mandelbaum certainly thought so, and so did Ewing (1947). The matter is worth further thought. But for the time being, and on the basis of the Mandelbaum proposal to look at the relation of fittingness as what unifies various moral experiences, we leave our readers (and ourselves) with these questions:

- Assuming that experiences of fittingness are what unifies our moral experiences, how interesting is this sort of unity? 
- Does it reveal some structurally complex element of our moral experience that is interestingly distinct from one's sense that some action (or response) is morally obligatory or right?

We now pass on to our next question about what, if anything at all, is distinctive of moral phenomenology.

\section{Distinctiveness}

Rather surprisingly, although Mandelbaum's work in his 1955 book is marked by much care given to phenomenological detail, what he says about distinctiveness seems inadequate - for reasons we will get to in a moment. Our own view of the matter is that there is no single element or feature of moral phenomenology that is distinctive of such phenomenology qua moral, even if one only considers, say, direct moral experiences of obligation. Rather, we think that there is a small set of characteristics - some of them possessed by prototypical moral experiences of the sort featured in Mandelbaum's work, and some of them associated with such experiences - that collectively serve to pick out at least a wide range of prototypical moral experiences. Experiences that lack one or more of the characteristics in question might still qualify as moral experiences, if the non-typical cases bear enough resemblance in the relevant respects to the prototypical, paradigmatic cases. There are four such characteristics of prototypical moral experiences worth noting.

1. Felt independence. We begin again with Mandelbaum. Recall the two layers of phenomenological description in connection with direct moral judgments: felt reflexive demand and apprehension of fittingness. One might look to either or both of these features - their respective phenomenologies - as a basis for distinguishing moral from non-moral experiences. But Mandelbaum (71) rejects the idea that there is some special, distinctive kind of fittingness that one apprehends in making direct moral judgments (or moral judgments of any sort) that is of a peculiar moral sort. He maintains that the relations of fit and unfit are generic and not peculiar to morals, and so he denies that apprehension of this relation in contexts of moral choice distinguishes moral from non-moral experience.

What about the aspect of felt demand, as perhaps distinguishing moral from non-moral phenomenology? As we explained, for Mandelbaum a felt demand involves the experience of a force having a direction and a source. And for experiences of felt moral obligation, the demand in question is experienced as being 'objective'. In explaining this sort of objectivity, Mandelbaum calls attention to experiences involving perceived alternatives in a situation in which one experiences the alternatives as involving moral 
choice, and he distinguishes such experiences from ones in which the perceived alternatives are not experienced as involving moral choices:

This feeling of obligation appears as independent of preference, as many of the alternatives within our experience do not. Where neither alternative has this character, where our choices are wholly matters of preference or desire, the choice which we face does not appear as a moral choice. However, let either alternative appear not as a preference, but as an "objective" demand, and I feel myself to be confronted by a moral issue, by a categorical imperative, by an injunctive force which issues from one of the alternatives itself. (50)

According to this suggestion, then, felt demands involve moral choices as opposed to non-moral choices when they are experienced as being categorical, in the sense of being experienced as independent of one's preferences.

This appeal to felt independence may help distinguish moral from some types of non-moral experience, but this way of understanding objectivity or categoricalness fails to draw any line between the phenomenology of direct moral judgments and the phenomenology of direct judgments of, say, etiquette. When meeting someone for the first time, one often experiences a felt demand to smile, shake hands, and so forth. This demand (we report) is felt at least on some occasions quite strongly. The same may be said for table manners and for a broad range of matters of etiquette that do not (all of them) seem to be matters of what morality demands, despite obvious overlap in demands. Rude behavior is sometimes immoral because it is rude, but in cases of 'mere' etiquette one still may feel an 'external' felt demand. The sense of a demand being anchored 'out there', in the desire-independent and preferenceindependent circumstances that one faces, thus holds as much for etiquette as it does for morals. This is a now-familiar theme featured in a well-known paper by Philippa Foot (1972). Although categoricalness of some sort has been often thought to be distinctive of moral judgments and associated experiences, this feature is not sufficient to uniquely pick out such judgments and experiences. Still, categoricalness (however this idea is to be spelled out precisely) is characteristic of typical moral experience.

2. Reasons. If one follows Mandelbaum, moral experiences of direct obligation, as well as removed moral experiences, are responses to an apprehension of fittingness. Fittingness, of course, is experienced as a relation that obtains between some action, attitude, or character trait, and some features of a circumstance (or set of circumstances) that provide reasons for that action, attitude, or character trait-reasons that 'call for' a certain response. One characteristic feature of moral (as opposed to non-moral) responses (and the experiences they involve) is one's apprehension of (or at least reaction to) moral reasons, where the notion of a moral reason is understood in terms of such considerations as respect, well-being, impartiality, autonomy, and harm that one takes to be of deep and fundamental 
moral significance. So the idea would be that prototypical moral experiences - both direct and removed - involve apprehension of (or some sensitivity to) facts about how actions and character traits bear on considerations of the respect for and well-being of persons and perhaps other sentient creatures, or how actions and character traits bear on considerations of impartiality, and so forth. We don't have to suppose that such considerations qua moral can be sharply defined and, correspondingly, we don't have to suppose that experiences can be neatly sorted into the moral and the nonmoral. Rather, the idea is that there is a range of types of consideration that seem central to a moral outlook, and characteristic of much moral experience (if not all) is an apprehension or some awareness of such features as part of the circumstances calling for a moral response.

So far, we have been investigating moral experiences of obligation and value, both direct and removed, searching for elements that might be characteristic of prototypical instances of such experiences as distinctively moral. However, it might be that in order to capture what is characteristically distinctive of moral experiences, one must look outside those particular experiences - call them first order moral experiences - to experiences that are associated with or perhaps take as their object first order moral experiences (or at least some element of them). There are two such characteristics of this sort: felt importance and reactive moral attitudes. Let us consider them further.

3. Felt importance. Many people take moral considerations to be very important to their personal and social lives. One way in which this felt importance may be manifested is motivational-as when a person not only experiences a felt moral demand, but also experiences the demand as being motivationally very strong or compelling. Of course, individuals will vary from one another and from time to time in how strongly they feel a moral demand, speaking now of direct moral experiences. However, another way in which felt importance is manifested is in one's beliefs-beliefs about the normative authority of moral considerations vis-à-vis competing nonmoral ones. ${ }^{11}$ It is the second way that we are mainly calling attention to here. The idea is that a certain kind of reflection on one's direct and removed moral experiences characteristically (at least among mature and morally well-trained agents) prompts the sense or the thought that moral considerations have a very high if not overriding normative significancethat moral reasons, because of the kinds of reasons they are, are personally and socially of very great importance.

4. Reactive moral emotions. We have not said very much in this paper about moral emotions - including moral emotions such as guilt and indignation - that constitute fitting responses or reactions to one's apprehension of moral wrongdoing by oneself and others respectively. Call the moral experiences constituted by such emotions second order moral experiences, since they are directed toward actions apprehended or believed to be 
morally wrong. Experiences constituted by such emotions have a phenomenology, and how such emotively charged experiences are related, for instance, to the phenomenology of direct moral judgments as Mandelbaum understands them is not something we can explore here. However, just as a sense of felt importance is plausibly thought to be a proper reaction to moral experiences of direct moral obligation, so also does it seem plausible to think that reactive moral emotions and attitudes (including, but not restricted to, the ones just mentioned) are proper responses to the sorts of direct and removed moral experiences described in Mandelbaum's work.

On the basis of these reflections we leave in our trail yet another question:

- Assuming that there is no one feature that is distinctive of all and only moral experiences, are there characteristics (including dispositional ones) that are distinctive of prototypical experiences qua moral? If so what are they and how are they related to moral experiences of obligation and value?

\section{Why moral phenomenology?}

The relevance of facts about moral experiences for matters of moral theory is more or less taken for granted. How much importance it should be accorded is controversial. But what interests us in this section is Mandelbaum's claim that there is a kind of methodological priority that should be accorded to phenomenological description.

Mandelbaum's case for the priority of his phenomenological approach involves arguing that other methods of ethical inquiry ${ }^{12}$ either appeal at bottom to facts of moral phenomenology or, as in the case of the "contentual' method of reflective equilibrium, the methods beg important normative questions and thus foil any attempt to provide an appropriately neutral basis from which to conduct ethical inquiry. By contrast, because his 'structural' method abstracts from the contents of moral judgments, this approach is sufficiently normatively neutral for purposes of tackling the main theoretical task of ethics - that of discovering a valid standard (or standards) for our moral judgments. So, according to Mandelbaum, his 'structural' phenomenological method is the only non-question-begging methodology that is suitable as a basis for ethical inquiry.

We can't pause here to consider in detail Mandelbaum's defense of his favored phenomenological approach. Rather, we simply observe that even were Mandelbaum's priority claim on behalf of his methodology indefensible, it could still be the case that phenomenological description of moral experience can be a basis for reaching important results in moral theoryincluding both normative moral theory and metaethics. So, we leave the reader with these questions about the import of moral phenomenology: 
- Should phenomenological description be afforded some sort of methodological priority in ethical inquiry?

- If not, does such description play an important role in moral theorizing anyway?

\section{Moral phenomenology and moral theory}

We simply can't leave the question about philosophical payoff up in the air; there is no sense in dwelling on phenomenological description of moral experience unless there is some prima facie reason to think that it will yield at least modest dividends in normative moral theory, metaethics, or both. So, in what follows, we briefly sketch a case for this optimistic assessment of phenomenological inquiry into moral experience. We have selected four issues - some of them featured in Mandelbaum's work - that strike us as being likely candidates that might benefit from work in moral phenomenology.

1. Teleology vs. Deontology. Teleological (consequentialist) moral theories are at odds with the phenomenology of direct moral experience. Mandelbaum argued for this claim on the basis of his observation that in responding to morally charged situations, one typically does not have the experience of basing one's verdict about one's obligations on a summation of the expected intrinsic value of the consequences of alternative actions. The point is not that people never do such calculating in cases of direct moral judgment, but that they just typically do not: moral experience in the case of direct moral judgments does not fit well with the account the consequentialist gives of obligation. This observation isn't a decisive blow against consequentialist views, of course. ${ }^{13}$ Our point here is simply that the phenomenology of direct moral judgments is in tension with consequentialist accounts of the basis of moral obligation. And so, to the extent to which one puts methodological weight on considerations of moral phenomenology, one will favor non-consequentialist views in normative ethics.

2. Monism, pluralism, and particularism. Above, in section V, we touched upon how the data of moral phenomenology seemingly count against ethical monism. As we mentioned, further phenomenological description may help in the debate between pluralists and particularists. Let us say just a bit more about this issue. According to Ross's theory of prima facie duties, in cases of conflict among the duties, the most 'stringent' of the competing prima facie duties is one's all-things-considered duty. Ross's view involves a kind of 'atomistic' approach to how one comes to make all-things-considered moral judgments in cases of such conflict. This kind of atomism can be expressed using Mandelbaum's analysis of direct moral judgments, as follows. In cases of conflicting prima facie duties, each morally relevant feature of the situation that grounds a prima facie 
obligation has an individual 'vector force' pressing on the agent, so to speak, and the prima facie obligation with the strongest net vectorial normative force grounds one's all-things-considered duty. On Mandelbaum's view, this understanding of moral stringency is too 'segmented', and the proposal he suggests fits well with particularist views about the silencing and reversal of morally relevant features. Mandelbaum's example is nice (76-7). He describes a case in which someone did you a large favor by intervening on your behalf - thus saving you your job, which was in jeopardy because of the unjustified actions of a vindictive co-worker. You and she are now (years later) in different jobs, and the question of whether she should retain her current position arises. You are asked by an administrator what you think about the matter. You honestly think she is not qualified. On Ross's view, you face a prima facie duty of gratitude and a competing prima facie duty of truthfulness, and the most stringent of the duties is your all-thingsconsidered duty. Mandelbaum thinks that Ross's view gets the phenomenology of many such cases all wrong. Granted, you have a standing prima facie obligation of gratitude to this former benefactor, but (so he argues) in this particular case the 'essential nature' of the situation makes giving your honest opinion the most fitting action to perform. He doesn't put it this way, but one might say that in these circumstances as Mandelbaum describes them, your duty of gratitude toward your benefactor is not merely outweighed by your duty of truthfulness (something Ross could allow), but rather is silenced: you judge that truthfulness is the fitting response, and that helping your benefactor by lying to save her job is unfitting.

Considerations of moral phenomenology, then, seem to bear on disputes between monists, pluralists, and particularists.

3. The primacy of character: morality of demand and morality of aspiration. Three batteries of morally relevant concepts (facts, considerations) are often distingushed: the deontic, the aretaic, and those of non-moral value. Debates over the 'structure' of moral theory have to do with whether one of these three sets is more basic than the remaining two. Maintaining some priority among these clusters of concepts is what distinguishes deontological theories, virtue-based theories, and versions of consequentialism. Some defenders of virtue ethics, for example, maintain that considerations of character - of virtue and vice - are more basic than considerations of obligation. We tend to think that such 'priority' disputes are misplaced in supposing there is some priority among the sets of evaluative concepts in play.

But we do think that even if considerations of character are not somehow conceptually or ontologically primary in relation to considerations of obligation (and perhaps non-moral value), character is indeed primary, in a certain way, for understanding the phenomenology of moral experience. Henri Bergson (1932) distinguishes between what he calls a morality of 'pressure' (of duty) and a morality of 'aspiration' (of ideals). This distinction 
seems to coincide with moralities associated (perhaps mistakenly) with Kant and with Aristotle, respectively. Our thought is this: the specific, distinctive nature of one's moral experiences is going to be importantly shaped by one's character; so, when it comes to understanding differences in specific moral phenomenology among different moral agents, considerations of character are going to be primary. After all, the moral experiences of a merely morally continent person are going to be different in important ways from the moral experiences of the Aristotelian agent whose desires are in harmony with what she experiences as morally fitting. We leave open here whether recognition of this difference in moral phenomenology across different character types serves to undermine Mandelbaum's phenomenological description of direct moral judgments. Certainly, questions about a person's character at a time, and about how it importantly shapes that person's moral experiences, constitute a large topic that will require both philosophical reflection and a great deal of empirical investigation.

4. Moral realism. Moral realists and defenders of error theories are fond of appealing to the phenomenology of moral experience in support of their favored moral metaphysics. We ourselves would maintain, however, that this appeal is too hasty, and that the phenomenology of moral experience is non-committal on this particular, refined metaphysical issue. On the one hand, Mandelbaum's phenomenological description does clearly support the idea that morality is in some sense objective. In particular, Mandelbaum's phenomenal argument against non-cognitivism and any form of metaethical subjectivism seems right to us: whatever emotions, feelings, or non-cognitive attitudes accompany moral judgments or even perhaps evoke them, these elements of moral experience do not appear to be the basis of obligation. Rather, in many cases one experiences various noncognitive states as themselves fitting reactions to what one takes to be 'called for' by the objective features of the situation one confronts. In situations where what triggers a moral judgment is an intuitive emotional response, one still experiences the response as demanded by the situation that one confronts or is contemplating. The phenomenology of moral experience clearly favors a kind of moral objectivity that is not compatible with emotivism, subjectivism, and kindred old-time metaethical views.

But times have changed since the days of 'analytic' metaethics, and in the present post-analytic era one finds versions of expressivism that claim to accommodate the deeply embedded trappings of moral thought and discourse, including the 'objective pretensions' of moral phenomenology. The matter, we think, is especially delicate - and especially worthy of careful phenomenological scrutiny. What we tend to think is that the objectivist moral phenomenology Mandelbaum described is not committed to a realist moral metaphysics - because the experience of fittingness does not purport to represent fittingness as a relation 'out there' in the fabric of reality, a relation the obtains (or fails to obtain) independently of one's own reactive 
attitudes. (Independence of one's own desires and preferences is one thing, whereas independence of one's own fittingness-sensibility is quite another.) ${ }^{14}$ But this matter requires more attention than we can possibly give it here. So, here again are a few more questions:

- What results might one reach about the underlying features of moral obligation and value on the basis of phenomenological description?

- What issues in metaethics (including questions about moral realism, moral semantics, and moral epistemology) might an investigation into moral phenomenology help resolve?

- Does moral phenomenology comport better with moral realism than with moral irrealism (or vice versa), or is it neutral on this metaphysical issue?

\section{Conclusion: help from empirical psychology?}

We ourselves are not settled on matters of moral phenomenology and their significance for moral theory. We do know that moral phenomenology has not been a focus of much attention by analytic philosophers. And we hope that changes. In the meantime, we want to conclude by mentioning something we think is fairly obvious that has to do with phenomenological investigation. Mandelbaum's phenomenological description of moral experience probably relied almost entirely upon his own experience, which he assumed was widely shared, at least by his audience. Recently there has been much interest by scientists in the moral judgments of individuals and groups and some of this research clearly bears on the various questions we have raised about the scope, unity, and distinctness of moral phenomenology. ${ }^{15}$ And this is at it should be. Phenomenological description of our moral experiences is not something one can do exclusively from an armchair. ${ }^{16}$

\section{Notes}

1. All Mandelbaum references are to his 1955 book.

2. In Horgan \& Timmons (in progress A and B).

3. As we are here using the term 'belief', the claim that moral judgments are occurrent moral beliefs is intended to be non-contentious; the claim is that moral judgments are occurrent psychological states of the kind characterizable in ordinary discourse via 'believes-that' constructions. Moreover, we argue in other places (Timmons (1999), Horgan \& Timmons $(2005,2006)$ ) that a metaethical expressivist need not deny that moral judgments are beliefs.

4. See Dreyfus \& Dreyfus (1990) on the phenomenology of ethical comportment.

5. Here is where issues in moral phenomenology are intimately related to issues in the phenomenology of agency-issues we plan to explore in future work. For discussion of the phenomenology of spontaneous, non-reflective agency, see Horgan and Tienson (2003) and Horgan, Tienson, \& Graham (2003). 
6. For defenses of the thesis that there is a phenomenology of intentionality, see for example Strawson (1994), Siewert (1998), Horgan \& Tienson (2002), Horgan, Tienson, and Graham (in press), and Pitt (2004).

7. A self-evident moral proposition is plausibly understood as one the proper understanding of which is sufficient for grounding justified belief in, and possible knowledge of, the proposition. See Audi (2004: 48-54). If indeed there are self-evident moral propositions, then one would expect the phenomenology of understanding to play an important role in the epistemology of self-evidence.

8. For an elaboration of the suggestions in this paragraph, see Horgan and Timmons (2006).

9. Here, we are putting the project of investigating underlying unity in a way that is meant to be neutral between competing metaethical views about moral properties - e.g., competing views about whether there are such properties at all, about whether (if there are) they are natural or non-natural.

10. In $\S$ VIII below we return to this issue contrasting Ross/Audi pluralism with particularism.

11. The rubric 'felt importance', as we are using it here, thus includes believed importance. We are not talking about sensory feels, and also one can believe a consideration important without necessarily experiencing any distinctive emotion about it. We would maintain that believed importance still falls within the purview of moral phenomenology, however, for at least two reasons. First, we side with those who hold that occurrent beliefs of any sort normally have a distinctive phenomenology; thus, so do beliefs about what is important. Second, the tinge of motivational hotness typically is present as a phenomenological aspect of beliefs about what's important. (Note that the construction 'I feel that...' can be used to express a belief, and is often most naturally used when the belief thus expressed has felt importance.).

12. Besides various forms of the phenomenological method, Mandelbaum (ch.1) also considers what he calls 'metaphysical', 'psychological' and 'sociological' methods.

13. As Mandelbaum points out (73), consequentialists are going to deny that they are attempting to remain consistent with moral phenomenology.

14. For a brief defense of the claim that moral phenomenology does not carry moral realist commitments, see Horgan and Timmons (2006). See also Kirchin (2003).

15. See for example, Haidt (2001) and Greene \& Haidt (2002).

16. Thanks to Joshua Knobe, Michael Gill, David Shoemaker, Walter SinnottArmstrong, and the audiences at the Arizona Moral and Political Philosophy Conference (Arizona State University, January 5, 2005) and at the Pacific Division APA Meeting (San Francisco, March 24, 2005) for very constructive comments on this paper.

\section{References}

Audi, R. 2004. The Good in the Right. Princeton \& Oxford: Princeton University Press.

Bergson, H. 1932. Two Sources of Morality and Religion. R. A. Audra and C. Brereton (trans.).

Garden City, NJ: Doubleday Anchor Books, 1935. 
Dreyfus, H. \& Dreyfus, S. 1990. 'What is Morality? A Phenomenological Account of the Development of Ethical Expertise'. In Rassmussen, D. (ed.), Universalism vs. Communitarianism. Cambridge, MA: MIT Press.

Ewing, A. C. 1947. The Definition of Good. New York: Macmillan.

Foot, P. 1972. 'Morality as a System of Hypothetical Imperatives.' Philosophical Review 81: 305-16. Reprinted in P. Foot, Virtues and Vices, Oxford: Oxford University Press, 2002.

Greene, J., and Haidt, J. 2002. 'How (and where) does moral judgment work?' Trends in Cognitive Science 6: 517-23.

Harman, G. 1977. The Nature of Morality. Oxford: Oxford University Press.

Haidt, J. 2001. 'The Emotional Dog and Its Rational Tail: A Social Intuitionist Approach to Moral Judgment.' Psychological Review 108: 814-34.

Horgan, T. \& Tienson, J. 2002. 'The Intentionality of Phenomenology and the Phenomenology of Intentionality'. In D. Chalmers (ed.), Philosophy of Mind: Classical and Contemporary Readings. New York: Oxford University Press, 520-33.

Horgan, T. \& Tienson, J. In press. 'The Phenomenology of Embodied Agency'. In J. Joao Saagua (ed.), Mind and Action III.

Horgan, T., Tienson, J. \& Graham, G. 2003. 'The Phenomenology of First-Person Agency'. In S. Walter and H. D. Heckmann (eds.), Physicalism and Mental Causation: The Metaphysics of Mind and Action. Exeter: Imprint Academic, 323-40.

Horgan, T., Tienson, J., \& Graham, G. In press. 'Phenomenal Intentionality and the Brain in a Vat'. In R. Schantz (ed.), The Externalist Challenge: New Studies on Cognition and Intentionality. New York: de Gruyter.

Horgan, T. \& Timmons, M. 2005. 'Morality without Moral Facts.' In J. Dreier (ed.), Contemporary Debates in Moral Theory. Oxford: Blackwell.

Horgan, T. \& Timmons, M. 2006. 'Cognitivist Expressivism'. In T. Horgan and M. Timmons (eds.), Metaethics After Moore. Oxford: Oxford University Press.

Horgan, T. \& Timmons, M. 'Moorean Moral Phenomenology'. In progress A.

Horgan, T. \& Timmons, M. Moral Phenomenology (tentative title). In progress B.

Kirchin, S. 2003. 'Ethical Phenomenology and Moral Realism.' Ethical Theory and Moral Practice 6: 241-64.

Köhler, W. 1938. The Place of Value in a World of Facts. New York: Liveright.

Mandelbaum, M. 1955. The Phenomenology of Moral Experience. Glencoe, IL: The Free Press.

Pitt, D. 2004. 'The Phenomenology of Cognition or What is it Like to Think That P?'

Siewert, C. 1998. The Significance of Consciousness. Princeton: Princeton University Press.

Strawson, G. 1994. Mental Reality. Cambridge: The MIT Press.

Timmons, M. 1999. Morality without Foundations. Oxford: Oxford University Press. 